\title{
PASPAHEGH : VISUALIZING A SEVENTEENTH- CENTURY ALGONQUIAN INDIAN VILLAGE IN THE VIRGINIA CHESAPEAKE
}

\author{
Crandall Shifflett \\ History Department \\ Virginia Tech \\ Blacksburg \\ Virginia \\ USA \\ shifflet@vt.edu \\ Virtual Jamestown (http://www.virtualjamestown.org/)
}

\begin{abstract}
The Paspahegh Project is a reconstruction of an Algonquian Indian village in seventeenth-century Virginia. It is a collaborative venture involving an historian, computer programmer, a visual artist and two public school teachers and their students. The project joins the latest technologies and visualization techniques to textual, cartographic, and archaeological evidence to produce a virtual reality model of the village for teachers, students, and the general public. The model will be published on the Virtual Jamestown web site and, funding permitting, rendered in the form of an educational game for distribution in DVD format.
\end{abstract}

\section{INTRODUCTION}

The Algonquian Indian village of Paspahegh, located just six miles north of Jamestown, Virginia, was the home of the Paspahegh Indian tribe, the first group of native people to make contact with the English in 1607. Textual, cartographical, and archaeological sources provide revealing accounts of Anglo-Indian encounters from the moment of arrival until the burning of the village and decimation of the tribe in 1610 . John Smith left detailed descriptions, including a dramatic telling of his personal battle with Wowinchopunck, the Paspahegh weroance, as they struggled to drown one another in the river. Smith's remarkable map of Virginia locates the village on the bank of the Chickahominy River as it empties into the James River [1]. Another map of Spanish ambassador Pedro de Zuniga, called the "Zuniga map," also locates the site geographically [2]. Most valuable, an archaeological survey in the 1990s provides a layout of Indian longhouses, burial sites, and agricultural areas and reports of artefacts found in the excavation [3]. This richly detailed record on the village provides a unique opportunity to recapture the everyday life and times of one of the thirty-one Indian tribes to compose the Powhatan chieftancy.

The Paspahegh Project is a collaborative venture involving an historian, computer programmer, a visual artist and two public school teachers [4]. Together our goal is to employ the latest technologies and visualization techniques, first to build a digital model and ultimately to build an educational game that allows students to explore Paspahegh based upon characters through whom Chesapeake Algonquian life and culture might be 
unfolded. We are in the early stages of this work but have built a prototype which we continue to develop [5]. The purpose of this essay is to provide some of the rationale for the project and solicit a critical assessment of the use of visual techniques to reconstruct the lost world of the Algonquian Indians.

\section{RATIONALE}

Janet Murray, Director of the Laboratory for Advanced Technology in the Humanities, refers to the computer as a 'storytelling genie in a lamp' [6]. In 1945, Vannevar Bush, a talented engineer who had served as Director of the Office of Scientific Research and Development throughout World War II, published an article in Atlantic Monthly on new tools that had great promise to give access and command over the accumulated knowledge of the ages [7]. The essay, As We May Think, provided an Emersonian perspective on how technology might revolutionize not only humankind's capacity to survey mountains of information but also give us the means to understand it better. Bush foresaw great promise in photography, microfilm, the copying machine, the fax, and numerical computing. But his most exciting prose he reserved, not for the machinery, but the process of cognition and understanding. He described a machine he called the 'memex' a wonderfully imaginative device of wheels, levers, and screens that performed like the human brain to follow intricate trails, make associations, and weave it all into revealing patterns. Interestingly, his model was the writing of history. More recently, visualization has emerged as a methodology with great potential to unlock the past in ways that join the memex metaphor to the graphical user interface. Now we have

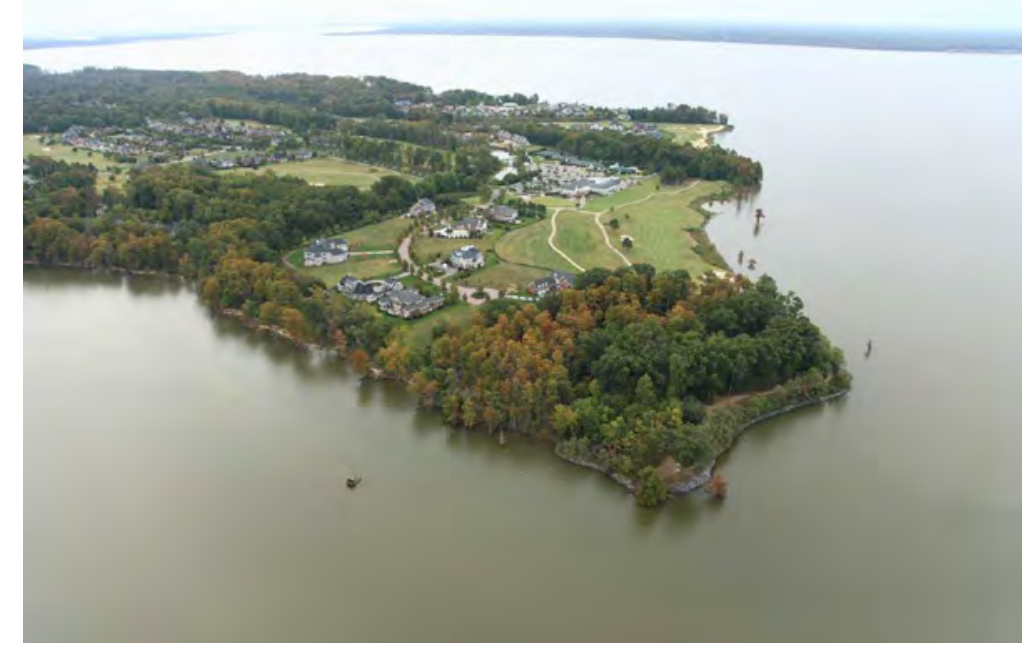
the means to exploit the machine's capacity for helping us think by letting us see what we are thinking about, thereby generating new, previously unimagined associations and patterns. This is what the Paspahegh Project aspires to do.

Figure 1. Paspahegh Today (Virtual Jamestown)

\section{THE PASPAHEGH VILLAGE}

The prototype makes use of an archaeological survey completed in 1994 as archaeologists hastened to complete a data recovery investigation of 44JC308, the site designation, prior to development of the area as a golf course (see figure 1). 
The Indian town of Paspahegh was situated at the mouth of the Chickahominy River on its east bank, about six miles northwest of James Fort. John Smith's 1608 Map of Virginia shows an unnamed town here. The entire area was known as Paspahegh, the name of the Algonquian-speaking group who occupied the town and hunted and fished the surrounding terrain and waters. Paspahegh was a dispersed town, meaning the town's houses were scattered across a large area with no evidence of fortifications or palisades. Instead, houses, gardens, and fallow fields spread over a terrace (ten to fifteen feet high) above the three waterways surrounding the town: the James River on the south (about two miles wide at the point), the Chickahominy (half-mile wide) on the west, and the Mattapamient Bay (north). Today the town is covered by a residential and golfing development called The Governor's Land at Two Rivers.

Paspahegh's environment provided all the needs of a Woodland Indian family: a deciduous forest for hunting, nuts, and firewood; flat, loamy soil for growing corn, squash, and beans; tuckahoe (tubers from the arrow arum plant, a major source of starch and carbohydrates); spawning runs of shad and herring in the spring; shallow bay waters to build fish weirs for catching fish at other seasons.

The survey found 48 complete or partial buildings, a mixture of houses and storage facilities (see figure 2). Houses were oval and ranged in between 14.5 and 31 feet long by 10.3 and 14.4 feet wide with wall posts set about 1.2 to 1.95 feet apart. Orientation of the structures varied typically from north-south to northwest by southeast. Two doors were located opposite one another but several houses had three or four doors. Despite English accounts noting their frequency in Indian houses, no traces of central hearths were found, perhaps due to not surviving or disintegrating over time. Built-in benches were also scarce in Paspahegh houses. Two of the five structures had benches along both sides of the house. Three houses had four or more postmolds that aligned to create a rectangle in the centre of the floor. The rectangle in structures 8 and 43 covered an area 7 by 4 feet in number 43 whose dimensions were 22.8 by 13.6 feet. The upright posts likely supported the sapling framework surrounding the smokeholes and also crosspieces to create a strong loft above the occupants. 
Three houses $(29,30$, and 33) were significantly longer (26.8 to 30.7 feet, compared to 23.7 for the next longest). They were not double-posted and they were set closest together at the highest point of the terrace, somewhat separated spatially from the others. Perhaps these were reserved for Wowinchupunk, the Paspahegh werowance and his wives, council, or other special residents.

Also descriptions reveal patterns of burial practices. In one plot, a man over 35 years of age was interred alone in a large pit, lying on his back with his head to the east and a necklace of tubular copper beads around his neck. At the time of death, he had four cavities, a good state of dental health among Indians at this time.

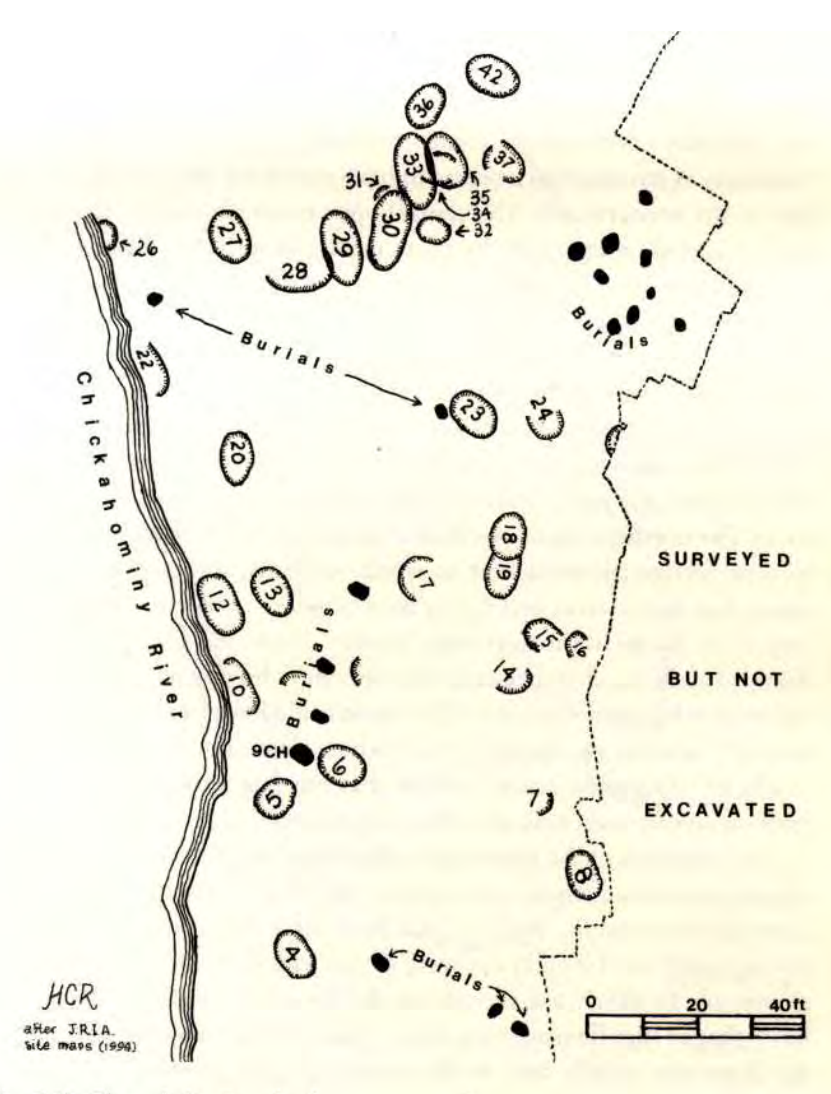

Figure 2: Site Survey adapted by Helen Rountree

\section{BUILDING THE PROTOTYPE}

The objectives of the Paspahegh project are to:

- Use advanced technologies to create new knowledge and knowledge in new ways

- Create a virtual simulation to be used as a PK-12 educational resource in the area of North American Indian history

- Employ open source software wherever possible or at the very least provide open access deliverables

- Demonstrate the research possibilities of projects focused on collaborative efforts in the fields of Arts, Creative Technologies, and Education

- Exploit the capabilities of gaming technology in the creation of "serious games" for education

- Add a new layer of interactive functionality to the Virtual Jamestown site

- Develop an effective "gaming pipeline" model, so that current and future complex digital assets can be moved efficiently between art and computer science-centric software.

\section{VIRTUAL PASPAHEGH}

Historical accuracy and authenticity will be priorities in the Paspahegh Project. Through the use of rare textual accounts of English-Paspahegh encounters, such as 


\section{EVA 2009 London Conference 6-8 July \\ Crandall Shifflett}

those of George Percy, Henry Spelman, William Strachey, or John Smith, the White watercolour drawings of Algonquian Indians of North Carolina, maps of John Smith and the Spanish ambassador de Zuniga, and the archaeological survey, a substantial body of material can be drawn upon to recreate a virtual Paspahegh. Still incomplete, visualization of the landscape was the first and one of the most time-consuming activities of the project. Contemporary reports of the area's flora and fauna require images that accurately reflect the plants, trees, and animal life. Integration of the historical knowledge will be accomplished through rollovers, pop-up windows, and with opportunities for interactive query (see screenshots below of the village being reconstructed). And all of this content will be delivered in three graded components: Level 1 - Pre-kindergarten through elementary; Level 2 - Middle and High School; and Level 3 - Beyond High School.
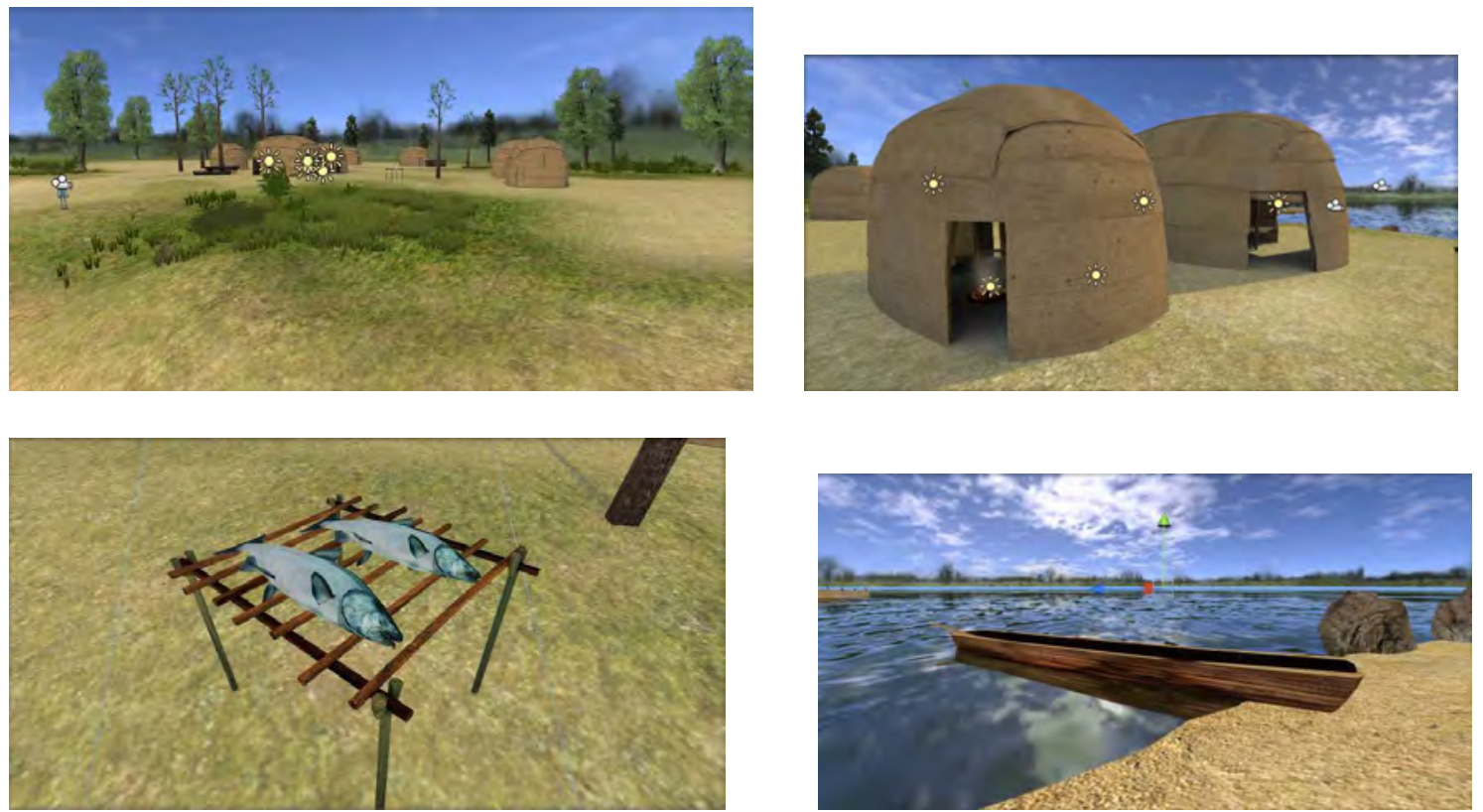

Figure 3. Screen Shots of Virtual Paspahegh (Dane Webster)

After the landscape and longhouse creations, the site will be augmented with representations of activities, such as raising maize, catching fish, canoe-building, and cooking fish. These common activities in Indian life for which we have graphical depictions, such as the watercolours of John White and the Theodor de Bry engravings, and written descriptions in first-hand accounts, such as Henry Spelman, an English boy who lived with the Algonquians for over a year and left an account of their culture (see figure 4) [8]. Pop-up windows will provide content on Indian practices of canoebuilding, fishing, and cooking. These activities will form the bases of pedagogical moments that combine historical content with visualizations to introduce topics of discussion, such as 'learning to fish', 'building a canoe', or more broadly 'coming of age'. An interactive avatar is being created to allow users of the site to pursue topics of interest or assume the identity as a specific character (i.e. a weroance, English governor, 


\section{EVA 2009 London Conference 6-8 July \\ Crandall Shifflett}

Indian boy or girl, English settler, warrior, or shaman). The educational team's students will build stories around the avatar-identity character, using historical bio-content as the basis for each role model. Beta testing of the educational game will be done in the classroom by the educational team working with their students to provide feedback and fine tuning.

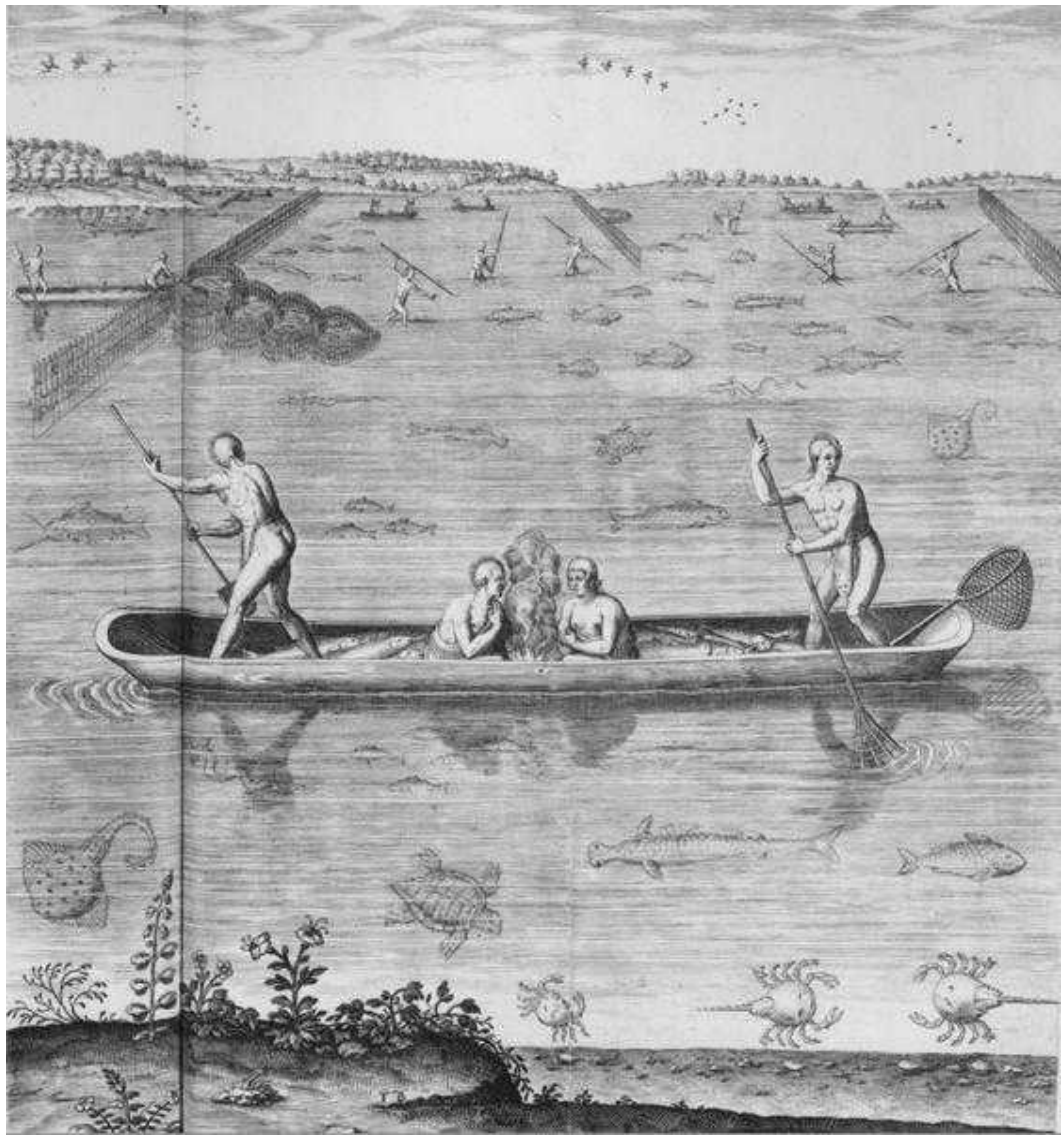

Figure 4. Their manner of fishynge in Virginia

(De Bry Engraving, Virtual Jamestown)

An example of how the storytelling genie and the memex metaphors may be tied to development of game content may be illustrated in the huskanaw ceremony. The huskanaw was a ritualistic induction into manhood which Indian boys underwent to mark their transition from children to adults [10]. It involved a mix of ceremonial celebrations, ritual beatings, vigorous physical activity, and feasting prior to a prolonged period of fasting, as boys were turned loose in the forest and required to survive on their own for long periods up to six weeks. During this time, boys cum men developed skills and attributes that marked them out for life as priests, shamans, warriors, and other roles of community life. Demonstrations of spiritual contact, feats of extraordinary athleticism, great success at killing game or the ability to say underwater for unusual amounts of time was thought to have marked out individuals for lives as priests, warriors, hunters, or chiefs. A variety of characters and stories may be built 


\section{EVA 2009 London Conference 6-8 July \\ Crandall Shifflett}

around the huskanaw as a coming of age, a deeply meaningful, and imprinting experience in Algonquian communities like Paspahegh.

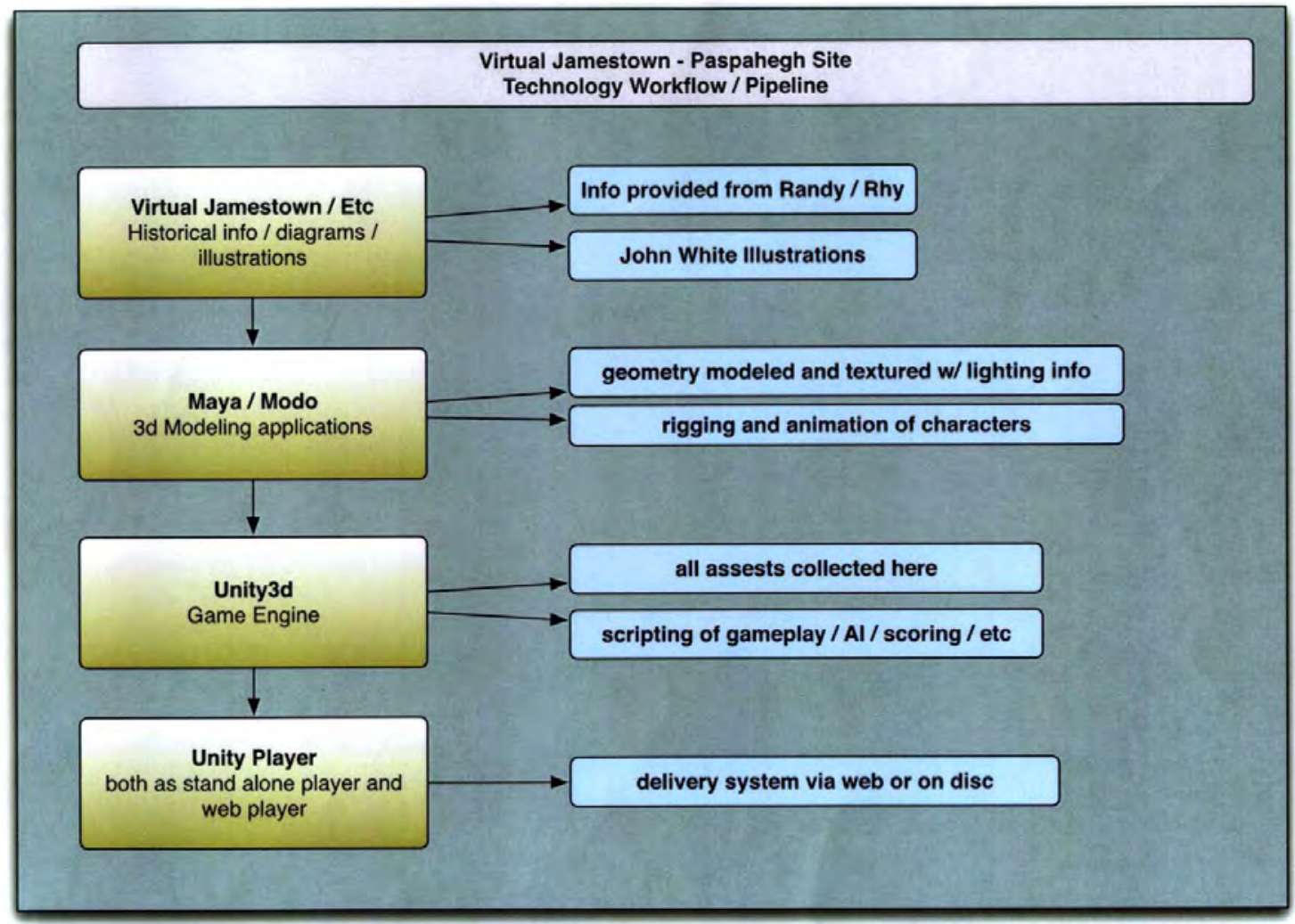

Figure 5. Flow Chart of Project Activities

\section{CONCLUSION}

The Virtual Paspahegh Project places a Chesapeake Indian village on its natural landscape in space, time, and within the historical context of English colonization in early seventeenth-century Virginia history. Such a representation allows scholars, teachers, students, and the general public to "see" Indian life and culture on the eve of imperial conquest. The reconstructed village will permit comparisons with other Indian villages, tribes, and cultures. As John White's watercolours have shown, not all Algonquian villages were of the same type. Some, like Pomeiocc, were circles with palisades for protection [8]. Why some villages were palisaded and others open raises questions about levels of security and comfort that prevailed in some areas and not others. Visualization of the village layout also will encourage analysis of internal configurations of housing, burial plots, agricultural areas, and cooking spots. It will evoke, for example, questions about rank and status attributions within the village, as for example, the situation of larger, more spacious longhouses clustered apart from others, suggesting the location of the chief weroance and his wives. Most importantly, the integration of the history of Indian-English encounters with virtual Paspahegh will 
EVA 2009 London Conference 6-8 July

Crandall Shifflett

bring deeper understanding to the life, work, and culture of Virginia's coastal Indians before the imperial conquest.

\section{ACKNOWLEDGEMENTS}

The author would like to acknowledge an Educational Advancement Collaboration grant from Virginia Tech, Office of the Senior Fellow for Resource Development, Arts Initiative that funded the prototype. Professors Dane Webster and his students in visual arts and Professor Yong Cao, Computer Programmer, have been indispensable parts of the Paspahegh Project Team. Another essential collaboration that will become even more valuable with game development and beta-testing is the educational team composed of two public school teachers and their students: Pete Lustig, Cave Spring High School, and Steve Sizemore, William Byrd Middle School.

\section{References}

[1] SMITH, J. Map of Virginia. http://www.virtualjamestown.org/maps1.html. 1608. Virtual Jamestown. On the fight with the Paspahegh chief and near drowning, see Virtual Jamestown, Philip L. Barbour, The Complete Works of John Smith: http://etext.virginia.edu/etcbin/ot2www-smith? specfile $=/ \mathrm{web} /$ data/collections/projects/jamestown/public/texts/www/smith.o $2 \mathrm{w}$ \&act $=$ surround\&offset $=2568506 \&$ tag $=$ Smith,+ John,+1580 -

[2] ZUNIGA, P. Virtual Jamestown http://www.virtualjamestown.org/paspahegh/context.html..

[3] LUCCKETTI, Nicholas M., HODGES, Mary Ellen and HODGES, Charles T. Paspahegh archaeology : data recovery investigations of Site 44JC308 at the Governor's Land at Two Rivers, James City County, Virginia. Williamsburg, VA. : James River Institute for Archaeology, Inc., 2000.

Hereafter referred to as 44JC308 site report.

The Governor's Land at Two Rivers developers' plans to build a golf course occasioned the final survey. The eighteenth hole was built over the Paspahegh site. For an Internet presentation of the history of the Paspahegh, archaeological footprint, and site contents, see Virtual Jamestown, http://www.virtualjamestown.org/paspahegh/paspaheghHome.html. For the adaptation of the survey map, see ROUNTREE, Helen C. and TURNER, E. Randolph. Before and after Jamestown : Virginia's Powhatans and their predecessors. Gainesville, USA, 2002.

[4] Professor Dane Webster, School of Visual Arts, Professor Yong Cao, Computer Science, and I (History Department) at Virginia Tech and two public school teachers, Pete Lustig, Cave Spring High School and Steve Sizemore, William Byrd Middle School, are the collaborators for Project Paspahegh.

[5] See http://www.virtualjamestown.org/paspahegh/examine.html and choose 3D Long House to see the prototype.

[6] MURRAY, J. Hamlet on the Holodeck: the future of narrative in cyberspace. Cambridge, USA, 1997. 
[7] BUSH, V. As we may think. Atlantic Monthly, July 1945.

http://www.theatlantic.com/doc/194507/bush; see also, Edward L. Ayers, History in hypertext, personal copy; David J. Staley, Computers, visualization, and history : how new technology will transform our understanding of the past, USA, 2003; Crandall Shifflett, Seeing the past : digital history as new model scholarship, JOLT. 3: 1 March 2007.

[8] SPELMAN, H. Relation of Virginia. http://etext.virginia.edu/etcbin/ot2wwwjamestown?

specfile $=/ \mathrm{web} /$ data/subjects/jamestown/persnarr.o2w\&grouping $=$ match\&docs $=\mathrm{t}$ ext\&query $=$ Spelman\&sample $=1-100 \& \mathrm{id}=\mathrm{J} 1040$

[9] See Virtual Jamestown: http://www.virtualjamestown.org/images/white debry html/jamestown.html. Also valuable, SLOAN, K. A New World: England's first view of America. Chapel Hill, USA, 2007. Online editions of The Records of the Virginia Company 1607-1624 and Philip Barbour's The complete works of John Smith, available in searchable text databases on Virtual Jamestown provide a treasure trove of data on Anglo-Indian encounters.

[10] GLEACH, F.W. Powhatan's world and colonial Virginia : a conflict of cultures. University of Nebraska Press, 1997. 